\title{
Laparoscopic appendectomy during pregnancy: an evidence-based review
}

\author{
Colin A. Walsh $\cdot$ Stewart R. Walsh
}

Published online: 5 December 2008

(C) Springer Science+Business Media, LLC 2008

Dear Editor,

We commend Jackson et al. for an interesting review of the role of laparoscopic surgery for surgical diseases during pregnancy [1]. They note that, in pregnancy, "laparoscopic appendectomy is considered by many to be the standard of care". However, we wish to highlight certain issues regarding laparoscopic appendectomy (LA) in pregnant patients which we believe are significant.

Although more than 600 cases of LA in pregnancy have been reported (and likely many more performed), much of the data are limited to individual case reports and small case series. McGory et al. recently reported 454 cases of LA in pregnancy, by far the largest series documented to date [2]. A subsequent publication from our unit incorporated an additional 183 cases from the literature, yielding a systematic review of 637 cases of LA in pregnancy [3]. We found that, although the rate of intraoperative complications during LA in pregnancy was low, the incidence of fetal loss following LA was significantly higher (5.6\%) than following open appendectomy $(3.1 \%, p=0.001)$. Conversely, the rate of preterm delivery $(<37$ weeks gestation) was higher in the open appendectomy group (8.1\%) compared with in the laparoscopic group (2.1\%, $p<0.0001)$. However, it is difficult to appreciate the significance of this, as we do not know how the surgical approaches compare with regard to the more clinically

\section{A. Walsh ( $\square)$}

Department of Obstetrics and Gynaecology, Addenbrooke's

Hospital, Cambridge University Hospitals,

Hills Rd., Cambridge, UK

e-mail: colwalsh@hotmail.com

S. R. Walsh

Department of General Surgery, Addenbrooke's Hospital,

Cambridge University Hospitals, Cambridge, UK important outcome of early preterm delivery ( $<34$ weeks). Additionally, data on neonatal outcome are not reported, although there were no neonatal deaths in the infants born preterm.

We agree with Jackson et al. [1], that an evidence-based approach to surgical intervention in pregnancy should be our aim. This is limited in the case of laparoscopic appendectomy, as currently there is no level I evidence to guide management of acute appendicitis in pregnant women. Furthermore, given the relative rarity of this condition, a sufficiently large randomized trial to address this issue seems unlikely. However, based on the evidence available, it would be prudent to note that a laparoscopic approach to appendectomy in pregnant women seems to confer additional risk, particularly to the fetus. If this surgical approach is indeed considered the current standard of care, then perhaps this needs to be challenged.

\section{References}

1. Jackson H, Granger S, Price R, Rollins M, Earle D, Richardson W, Fanelli R (2008) Diagnosis and laparoscopic treatment of surgical diseases during pregnancy: an evidence-based review. Surg Endosc June 14

2. McGory ML, Zingmond DS, Tillou A, Hiatt JR, Ko CY, Cryer HM (2007) Negative appendectomy in pregnant women is associated with a substantial risk of fetal loss. J Am Coll Surg 205(4): 534-540

3. Walsh CA, Tang T, Walsh SR (2008) Laparoscopic versus open appendicectomy in pregnancy: a systematic review. Int J Surg 6(4):339-344 